\title{
Alzheimer in the City
}

\author{
Jean-François Dartigues*
}

INSERM U 1219, Bordeaux Population Health, Université de Bordeaux, 146 rue Léo Saignat, 33076 Bordeaux, France

Received 6 June 2018 - Accepted 15 June 2018

\begin{abstract}
Alzheimer's disease was described in 1906, but it was only in 1987 that it was recognized as a public health problem with the actions of patient family associations. Despite successive Alzheimer plans, it remains a neglected and under-diagnosed disease. The lack of curative treatment and a clash of views between general practitioners and specialists explain these findings. Paradoxically, despite this neglect, Alzheimer's disease is receding in the city. This is the proof that prevention is possible.
\end{abstract}

Keywords: Alzheimer's disease / epidemiology / recourse to care / secular trends

Résumé - Alzheimer dans la Cité. La maladie d'Alzheimer a été décrite en 1906, mais c'est seulement en 1987 qu'elle a été reconnue comme problème de santé publique sous l'impulsion des associations de familles de malades. Malgré les plans Alzheimer successifs elle reste une maladie négligée et sousdiagnostiquée. L'absence de traitement curatif et une opposition de conception entre généralistes et spécialistes expliquent ces constatations. Paradoxalement, malgré cette négligence la maladie d'Alzheimer recule dans la Cité. C'est la preuve que la prévention est possible.

Mots clés : maladie d'Alzheimer / épidémiologie / recours aux soins / tendances séculaires

\section{Introduction}

Alzheimer's disease (AD) was described by Alois Alzheimer in 1906, but from a public health perspective, the disease has really existed since 1987 . Before 1987, AD was only considered as a rare disease for neurologists. In 1987, the Alzheimer Society was founded by patients and families. It is also the year of birth of the disease for the media and the City when Yasmina Aga Khan announced on television that her mother, Rita Hayworth, has Alzheimer's disease.

With this announcement, in the City, the disease really existed because it was not only an illness for the elderly but also a major illness and burden for their families, due to the loss of a relationship with a loved one, their progressive dependence and their behavioral disorders.

Another important year was 1998, twenty years ago, with the launch of donepezil, the first symptomatic drug not too badly tolerated, a Cholinesterase Inhibitor (ChI). Its efficacy was limited, with a 2 to 4 points gain in ADAS Cog compared to placebo after six months of use (equivalent to one to two points of Mini Mental State Examination (MMSE)). However, this treatment was the first real hope for patients, families and doctors. In France, the first prescription of the drug had to be

\footnotetext{
*Correspondence: jean-francois.dartigues@u-bordeaux.fr
}

made by a specialist. This controversial decision will have important consequences for a disease not so rare as that with 600000 cases in France, 120000 new cases per year (One million prevalent cases for all type of Dementia and 200000 incident cases). This represents about five to seven cases followed by a general practitioner, if we limit ourselves to clinically probable Alzheimer's disease cases. Despite its frequency, the disease will have to remain a specialist's disease. With the emergence of a drug treatment, the disease really became a public health problem involving the whole health system.

With the ageing of the population and the foreseeable increase in the number of cases, with the prospect of a significant increase in health expenditure, illness gradually became a public health priority. Three consecutive national plans were proposed in France. The first plan (2002-2004) was essentially medical, with the creation of 350 memory consultations, one per health territory, and expert Centers in the management of Alzheimer's disease and related disorders, at least one per region. This organization reinforced the idea that $\mathrm{AD}$ was a disease for specialist. The second plan (2005-2007) recognized the disease as a long-term condition justifying $100 \%$ reimbursement of health expenses. The third plan (2008-2012) was the most important and allowed the development of medico-social structures adapted to the three important consequences of the disease (loss of social relations, dependency, behavioral 
disorders) in all health territories. Despite these efforts, the disease has remained very neglected in the city with less than one in three new cases diagnosed at the beginning stage and seen by a specialist and less than one in four cases treated by cholinesterase inhibitors (Pimouguet, 2016).

Because of this very high proportion of undiagnosed cases, the study of the disease in the City can only be done through the establishment of population-based cohorts.

\section{Population-based cohorts for Dementia in France}

For more than thirty years we have been aware that only a cohort constituted in the general population allowed us to have a good knowledge of the disease in the City, its number, its causes, its care, its consequences. This is the reason why we constituted the PAQUID cohort (Personne Agée QUID) (Dartigues, 1992) in 1988 in 75 parishes from the region around Bordeaux. Ten years later in 1999, we constituted with all French epidemiologists interested by AD the Three-Cities cohort in Bordeaux, Dijon and Montpellier (Three-Cities Group, 2003). Finally, we constituted the AMI cohort of farmers in the Bordeaux region in 2008 (Peres, 2012). These three cohorts were formed using the same method.

Elderly people older than 65 years were randomly chosen in electoral or social security list. Participants were seen at home by a psychologist. The psychologist collected information including socio-demographic and lifestyle characteristics, self-reported chronic diseases, medication consumptions, depressive symptoms, and functional status during face-toface interviews. In addition, participants underwent a comprehensive evaluation of cognitive function as well as an active screening of dementia. Dementia was actively diagnosed at each follow-up visit using a 3-step procedure. First, the trained psychologist administered an interview and a battery of neuropsychological tests evaluating memory, language, processing speed and executive functions. The interview comprised an evaluation of the recourse to care for cognitive problems: subjective cognitive complaint based on seven questions about self-perceived cognitive difficulties, complaint to a primary care physician (PCP), recourse to a specialist (neurologist, geriatrician or psychiatrist). The psychologist completed two scales for Instrumental Activities of Daily Living (Lawton scale) and Basic Activities of Daily living (Katz scale). She collected also leisure activities and hobbies. Finally, the psychologist gave her clinical impression on the coherence, the global cognitive state of the subject and the consequences of a possible cognitive decline on the social activities of the subject in an open commentary. In a second time, a neurologist or a geriatrician examined the participants who were suspicious of dementia based on the neuropsychologist's suspicion and decline in Mini-Mental State Examination (MMSE) score. The neurologist or geriatrician completed the Clinical Dementia Rating (CDR) scale on the basis of his clinical examination and of the psychologist data. Finally, an independent committee of neurologists reviewed all potential cases of dementia to obtain a consensus on the diagnosis according to the Diagnostic and Statistical Manual of Mental Disorders, Fourth Edition (DSM-IV), criteria and classified the subjects according to the etiology of dementia.

\section{Why does the disease remain so neglected in the City?}

There are many reasons for the high proportion of undiagnosed cases. The most important reason is the lack of efficacy of anti-dementia drugs and the absence of new treatments for twenty years despite enormous research efforts. Furthermore, the anti-dementia drugs have been particularly criticized in France with a recommendation for delisting by the Haute autorité de santé (HAS) since 2016. The cost of treatment in France in 2017 was only 90 million euros, compared with 250 million euros in 2005 . With no treatment, no diagnosis and even no disease... before the major complications of $\mathrm{AD}$. Another important reason is the opposition between the conception of dementia among general practitioners and specialists. Specialists make Alzheimer's disease a specific disease, even in the elderly, characterized by the presence of biomarkers in the brain and the cerebrospinal fluid. They thus define a preclinical stage of $\mathrm{AD}$, a prodromal stage and a dementia stage. The majority of general practitioners do not adhere to this conception and consider $\mathrm{AD}$ as a consequence of ageing that does not justify specific medical management before loss of autonomy or behavioral disorders.

We conducted a qualitative study with patients detected in our cohorts, their caregivers and their general practitioners (Harmand, 2017). The results confirm and refine the quantitative data. The patients consult a specialist especially when there is opposition between caregiver and patient, and when the medico-social resources are not sufficient in the territory. We showed that the disease was more aggressive with more behavioral disorders when the subject consulted a specialist (Pimouguet, 2015). As a result, the risk of death and institutionalization (Pimouguet, 2016) was higher if the specialist was consulted. These results were erroneously used to conclude that specialist management was deleterious. "It is very difficult, if not impossible, to draw the line between health and disease, between normal and abnormal". This sentence by Claude Bernard takes on particular importance here.

As with Age-related Macular Degenerescence, for which the same debate existed in the last century, only effective treatment can bring the positions of all physicians closer together.

\section{What is the future AD in the City?}

The best news of the last ten years for Alzheimer's disease in the city is the decreased risk found in multiple epidemiological studies. Decreases in the prevalence and/or incidence of $\mathrm{AD}$ at equal age have been seen in Spain, the Netherlands, Sweden, the USA, England, but not in Japan or China (Grasset, 2016). In France, we showed that the incidence of major cognitive impairment had decreased in the same proportions by comparing the Paquid study and the 3C study ten years apart (Grasset, 2016). Moreover, we showed that an even greater decrease in the prevalence of cognitive disorders was observed among farmers in Gironde by comparing Paquid and AMI (Peres, 2017). The reasons for this reduction in the risk of AD are multiple. 
The first reason is the general increase in the educational attainment of the population during the 20th century. A better level of education is accompanied by an increase in the brain's reserve capacity which enables it to better compensate for neurodegenerative lesions (Foubert-Samier, 2012). Another reason is linked to the decline in cardiovascular diseases thanks to better management of risk factors (hypertension, hypercholesterolemia, diabetes, smoking, heart disease). However, these reasons only partly explain the decline in risk. There are probably other factors that will be very important to discover.

Are we experiencing an unscheduled triumph analogous to a decreased risk of stomach cancer or death from tuberculosis? The future will tell.

\section{References}

Dartigues JF, et al. 1992. The Paquid epidemiological program on brain ageing. Neuroepidemiology 11(1): 14-18.

Foubert-Samier A, et al. 2012. Education, occupation, leisure activities, and brain reserve: a population-based study. Neurobiol Aging 33(2): 423 e15-25.
Grasset L, et al. 2016. Trends in dementia incidence: evolution over a 10-year period in France. Alzheimers Dement 12(3): $272-280$.

Harmand MG, et al. 2017. Description of general practitioners' practices when suspecting cognitive impairment. Recourse to care in dementia (Recaredem) study. Aging Ment Health: $1-10$.

Peres K, et al. 2012. Health and aging in elderly farmers: the AMI cohort. BMC Public Health 12: 558.

Peres K, et al. 2017. Trends in prevalence of dementia in French farmers from two epidemiological cohorts. J Am Geriatr Soc 65 (2): 415-420.

Pimouguet C, et al. 2015. Survival and early recourse to care for dementia: a population based study. Alzheimers Dement 11(4): 385-393.

Pimouguet C, et al. 2016. Effect of early referral to specialist in dementia on institutionalization and functional decline: findings from a population-based study. $J$ Alzheimers Dis 49(3): 819-828.

Three Cities Group, CS. 2003. Vascular factors and risk of dementia: design of the Three-City Study and baseline characteristics of the study population. Neuroepidemiology 22(6): 316-325.

Cite this article as: Dartigues J-F. 2018. Alzheimer in the City. OCL 25(4): D402. 